\title{
UTILIZAÇÃO DO FARELO DE CONCHAS DE VÔNGOLE NA ADSORÇÃO DE FÓSFORO E COMO CORRETIVO DA ACIDEZ DO SOLO
}

\author{
PAOLA A. V. LO MONACO ${ }^{1}$, ANTONIO T. MATOS ${ }^{2}$, VALDEIR EUSTÁQUIO JÚNIOR ${ }^{3}$, \\ IVAN C. A. RIBEIRO ${ }^{4}$, DENIS L. TEIXEIRA ${ }^{5}$
}

\begin{abstract}
RESUMO: Teve-se o objetivo de, com a realização deste trabalho, obter a curva de neutralização do $\mathrm{pH}$ de amostras dos horizontes A e B de um Latossolo Vermelho-Amarelo distrófico, utilizandose de farelo de conchas de vôngole (Anomalocardia brasiliana); além disso, avaliar a capacidade de adsorção de fósforo, obtendo-se a isoterma de adsorção de melhor ajuste aos dados obtidos. Verificou-se que o farelo de concha de vôngole apresenta potencial para uso como corretivo de acidez do solo e que a dose recomendada para correção do $\mathrm{pH}$ do horizonte A do Latossolo Vermelho Amarelo distrófico estudado foi de 2,92 $\mathrm{t} \mathrm{ha}^{-1}$, enquanto, para correção do horizonte B, foi de $3,35 \mathrm{t} \mathrm{ha}^{-1}$. O farelo de conchas de vôngole também apresentou alta capacidade de adsorção de fósforo, o que indica possibilidades de sua utilização em sistemas que visem à remoção deste elemento químico de águas residuárias. Os modelos de Langmuir e Freundlich ajustaram-se bem aos dados e podem ser utilizados para representar a isoterma de adsorção de fósforo.
\end{abstract}

PALAVRAS-CHAVE: resíduos de maricultura, correção da acidez do solo, remoção de fósforo, isotermas de adsorção.

\section{UTILIZATION OF GROUND CLAM SHELLS IN THE ADSORPTION OF PHOSPHORUS AND FOR CORRECTION OF SOIL ACIDITY}

ABSTRACT: The objective of this study was to obtain the curve of $\mathrm{pH}$ neutralization for samples of the horizons A and B of a dystrophic Rhodic Haplustox soil using ground clam shells (Anomalocardia brasiliana), as well as assess the capacity of phosphorus adsorption to obtain the adsorption isotherm that best fit to the data obtained. It was found that the ground clam shells present potential to be used in soil acidity correction and that the recommended dose for $\mathrm{pH}$ correction of horizon A of the dystrophic Rhodic Haplustox studied was $2.92 \mathrm{t} \mathrm{ha}^{-1}$, while for correction of horizon B was $3.35 \mathrm{t} \mathrm{ha}^{-1}$. The ground clam shells also showed high adsorption capacity for phosphorus, which indicates possibilities of its use in systems targeting the removal of this chemical from wastewater. The Langmuir and Freundlich models fit well to the data and may be used to represent the adsorption isotherm.

KEYWORDS: marine culture residues, correction of soil acidity, phosphorus removal, adsorption isotherms.

\section{INTRODUÇÃO}

O vôngole (Anomalocardia brasiliana) é um molusco bivalve que habita ambientes aquáticos arenosos ou lodosos, onde vive enterrado, sendo sua criação de grande importância do ponto de vista socioeconômico em algumas regiões da costa brasileira, tais como a região da Baía de Todos os Santos, na costa da Bahia (BISPO et al., 2004), e da Praia Grande, no Estado do Rio de Janeiro.

\footnotetext{
${ }^{1}$ Eng $^{\mathrm{a}}$ Agrícola, Professora, Doutora em Engenharia Agrícola, Instituto Federal de Educação, Ciência e Tecnologia do Espírito Santo, Câmpus Centro Serrano, paolalomonaco2004@yahoo.com.br.

${ }^{2}$ Eng ${ }^{\circ}$ Agrícola, Professor, Doutor em Solos e Nutrição de Plantas, Universidade Federal de Viçosa, Viçosa, MG, atmatos@ufv.br.

${ }^{3}$ Eng $^{\text {o }}$ Agrícola e Ambiental, M.s em Engenharia Agrícola, Doutorando em Engenharia Agrícola, Universidade Federal de Viçosa, Viçosa - MG, vejunior@yahoo.com.br.

${ }^{4}$ Graduando em Engenharia Agrícola e Ambiental, Universidade Federal de Viçosa, Viçosa, MG, ivan.ribeiro@ufv.br.

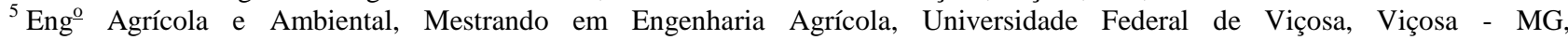
denisleocadioufv@yahoo.com.br.

Recebido pelo Conselho Editorial em: 14-2-2011

Aprovado pelo Conselho Editorial em: 16-5-2012
} 
No entanto, em muitas mariculturas, as conchas do molusco têm sido descartadas em locais inadequados, causando mau cheiro e degradação do meio ambiente adjacente e, quando dispostas nas praias, desconforto aos banhistas e prejuízos à paisagem. Logo, faz-se necessário o desenvolvimento de técnicas que possibilitem sua disposição no meio ambiente com menor impacto possível ou a reutilização desses resíduos de forma adequada.

Ultimamente, vem-se vislumbrando a possibilidade de utilizar o farelo da concha de vôngole (Anomalocardia brasiliana) como corretivo da acidez do solo, já que, de acordo com LEE et al. (2008), este marisco tem o carbonato de cálcio como principal constituinte de suas conchas.

Como a maioria dos solos brasileiros apresenta limitações ao estabelecimento e desenvolvimento de grande parte das culturas, em decorrência dos efeitos da acidez nas plantas, pesquisas têm sido realizadas utilizando resíduos alternativos ao calcário, como o lodo de esgoto caleado (FIA et al., 2005; SILVA et al., 2006), a escória de siderurgia (PRADO et al., 2003), dentre outros, em razão da elevada disponibilidade com que são descartados no meio ambiente e a possibilidade de corrigirem a acidez do solo.

Além da possibilidade da utilização do farelo de conchas de vôngole como corretivo da acidez do solo, a composição química (altos teores de carbonato de cálcio) dá indicativos de sua potencial utilização no tratamento de águas residuárias, especialmente na adsorção de fósforo. PARK \& POLPRASERT (2008) adaptaram um filtro constituído de farelos de conchas a um sistema alagado construído (Wetland construído) e obtiveram remoções significativas de $\mathrm{P}$ e $\mathrm{N}$ da água residuária em tratamento.

Para descrever as relações entre a concentração de determinado elemento químico adsorvido e sua concentração remanescente na solução de equilíbrio, têm sido utilizadas equações matemáticas denominadas isotermas. As isotermas de adsorção de Freundlich e de Langmuir têm sido frequentemente utilizadas em estudos de adsorção de metais pesados no solo (SOUZA et al., 2007; TITO et al., 2008; CHAVES et al., 2009a; CHAVES et al., 2009b; OLIVEIRA et al., 2010), em percolado de resíduo sólido urbano por resíduos de construção civil (MOREIRA et al., 2009; MOREIRA et al., 2010) e em escória de alto forno (MATOS et al., 2010a), tendo descrito satisfatoriamente o fenômeno.

De acordo com NOVAIS \& SMITH (1999), a isoterma de Freundlich é puramente empírica, suas constantes não têm significado físico, havendo decréscimo exponencial da energia de ligação com a saturação da superfície de adsorção. Já a isoterma de Langmuir tem a vantagem de possibilitar a estimativa da capacidade máxima de adsorção de fósforo (CPMA) e a constante relacionada com a energia de ligação.

Vários são os trabalhos nos quais se relata a utilização de isotermas de adsorção para estudar o fenômeno de adsorção de P nos mais variados tipos de solos (MOREIRA et al., 2006; CHAVES, et al., 2009b; FARIAS et al., 2009). Entretanto, pouca referência é encontrada na literatura no que se refere à adsorção de fósforo em resíduos, principalmente quando se utiliza o farelo de conchas de vôngole.

A substituição do calcário por resíduos alternativos na correção da acidez do solo torna-se opção interessante, já que possibilita seu descarte harmônico no meio ambiente, além de economia e preservação ambiental com a diminuição na extração e uso do calcário. No caso do tratamento de águas residuárias, a adsorção de fósforo pelo farelo de conchas de vôngole pode minimizar os inúmeros impactos causados pela eutrofização em corpos hídricos, já que pode remover um elemento químico diretamente associado a este fenômeno.

Objetivou-se, com a realização deste trabalho, obter a curva de neutralização do $\mathrm{pH}$ de amostras dos horizontes A e B de um Latossolo Vermelho-Amarelo distrófico, utilizando-se de farelo de conchas de vôngole (Anomalocardia brasiliana), além de avaliar a capacidade de adsorção de fósforo, obtendo-se a isoterma de adsorção de melhor ajuste aos dados obtidos. 


\section{MATERIAL E MÉTODOS}

As conchas de vôngole foram coletadas na Praia da Ilha da Madeira, em Mangaratiba, Costa Verde do RJ e, em seguida, trazidas ao Laboratório de Solos e Resíduos Sólidos do Departamento de Engenharia Agrícola, da Universidade Federal de Viçosa, onde os experimentos foram conduzidos.

\section{Avaliação do farelo de vôngole como corretivo da acidez do solo}

As conchas foram moídas em almofariz, de forma a se obter um farelo. O pó de conchas teve determinada sua eficiência relativa (ER) e o Poder de Neutralização (PN) de acordo com metodologia descrita por MATOS (2008), obtendo-se valores de 60,47\% e 95,40\% de $\mathrm{CaCO}_{3}$, respectivamente. De posse da eficiência relativa e do poder neutralizante, foi possível calcular o poder relativo de neutralização total (PRNT), obtendo-se o valor de 57,68\% de $\mathrm{CaCO}_{3}$. O material moído foi, então, passado em peneira de $0,30 \mathrm{~mm}$ (ABNT 50), sendo apenas o que passou (pó fino) utilizado nas análises. Com isso, o Poder Relativo de Neutralização Total (PRNT), no material utilizado nos ensaios, foi de 95,40\%. Esse pó fino foi misturado em amostras de $500 \mathrm{~g}$ dos horizontes A e B de um Latossolo Vermelho-Amarelo (LVA), textura argilosa, coletado na localidade denominada de "Tiro de Guerra", na cidade de Viçosa-MG, nas doses de $0 ; 20 ; 40 ; 160$ e $320 \mathrm{t} \mathrm{ha}^{-1}$. Nele, foi medido o pH em água, suspensão preparada na proporção de 1:2,5, utilizando-se, para isso, de um peagâmetro de bancada. As principais características físicas e químicas do horizonte A e B do LVA estão apresentadas na Tabela 1.

TABELA 1. Características físicas e químicas do horizonte A e B do LVA. Physical and chemical characteristics of A and B horizons of the LVA.

\begin{tabular}{|c|c|c|c|c|}
\hline Horizontes & pH em água & Teor de Argila & Matéria orgânica & $\begin{array}{l}\mathrm{CTC}_{\text {efetiva }} \\
\mathrm{cmol}_{\mathrm{c}} \mathrm{kg}^{-1}\end{array}$ \\
\hline $\mathrm{A}$ & 5,5 & 63,0 & 5,71 & 2,32 \\
\hline B & 5,0 & 72,0 & 3,02 & 0,94 \\
\hline
\end{tabular}

A mistura de solo e pó de conchas permaneceu sob condições de conteúdo de água equivalente às da capacidade de campo, em incubação, por um período de duas semanas, tempo requerido para que ocorresse a reação do solo com o corretivo de acidez e se alcançasse o equilíbrio. Ao final desse período, o material do solo foi secado ao ar e passado em peneira de $2 \mathrm{~mm}$ para medição do $\mathrm{pH}$ em água, numa proporção de 1:2,5, utilizando-se, para isso, de um peagâmetro de bancada.

Os dados obtidos foram submetidos à análise de regressão, a fim de se ajustar a equação de estimativa do valor de $\mathrm{pH}$ como função da dose aplicada de pó de conchas de vôngole. O gráfico da curva de incubação foi obtido utilizando-se do programa SIGMA PLOT 9.0.

\section{Adsorção de fósforo em farelo de vôngole}

Foi adicionada uma massa de 2,5 $\mathrm{g}$ do farelo de conchas, $20 \mathrm{~mL}$ das soluções de fósforo $(10 ; 20$; 50; 100; 200; 250; 300; 350; 400; 450; 475 e 500 mg L ${ }^{-1}$ de P), preparadas com $\mathrm{KH}_{2} \mathrm{PO}_{4}$ diluído em água destilada.

As suspensões foram colocadas em agitador vertical, por 8 horas, e posteriormente centrifugadas a $3000 \mathrm{rpm}$, por 10 minutos. O sobrenadante foi coletado para a quantificação da concentração de fósforo na solução de equilíbrio. Foram obtidas quatro repetições das suspensões preparadas com a adição das referidas soluções de P. A concentração de P no sobrenadante foi obtida pelo método fosfo-molibdílico e medição da absorvância em espectrofotômetro (EMBRAPA, 1997).

A quantidade de fósforo adsorvida ao farelo de conchas foi considerada como sendo a diferença entre as concentrações iniciais e finais do mesmo elemento na solução de equilíbrio, conforme MOREIRA et al. (2009).

A partir dos dados obtidos experimentalmente, foram construídas isotermas de adsorção, plotando-se a quantidade de $\mathrm{P}$ adsorvido na ordenada, e a concentração na solução de equilíbrio na 
abscissa. Os coeficientes das equações de Langmuir e Freundlich foram obtidos a partir das eqs.(1) e (2):

1) Langmuir

$$
\mathrm{S}=\frac{\mathrm{S}_{\mathrm{m}} \mathrm{K}_{\mathrm{L}} \mathrm{C}_{\mathrm{eq}}}{1+\left(\mathrm{K}_{\mathrm{L}} \mathrm{C}_{\mathrm{eq}}\right)}
$$

em que,

$\mathrm{S}$ - quantidade de fósforo adsorvido em $\mathrm{mg} \mathrm{g}^{-1}$ de farelo de vôngole;

$\mathrm{S}_{\mathrm{m}}$ - capacidade máxima de adsorção, $\mathrm{mg} \mathrm{g}^{-1}$;

$\mathrm{K}_{\mathrm{L}}$ - coeficiente relacionado à energia de ligação, $\mathrm{L} \mathrm{mg}^{-1}$, e

$\mathrm{C}_{\mathrm{eq}}$ - concentração de fósforo na solução de equilíbrio, $\mathrm{mg} \mathrm{L}^{-1}$.

2) Freundlich

$$
\mathrm{S}=\mathrm{K}_{\mathrm{F}}\left(\mathrm{C}_{\mathrm{eq}}\right)^{\mathrm{b}}
$$

em que,

$\mathrm{S}$ - quantidade de fósforo adsorvido em $\mathrm{mg} \mathrm{g}^{-1}$ de farelo de vôngole;

$\mathrm{K}_{\mathrm{F}}$ - coeficiente de adsorção de Freundlich, $\mathrm{L} \mathrm{mg}^{-1}$;

$\mathrm{C}_{\mathrm{eq}}$ - concentração de fósforo na solução de equilíbrio, $\mathrm{mg} \mathrm{L}^{-1}$, e

b - estimativa do parâmetro de ajuste, adimensional.

As equações relativas para dois modelos matemáticos de isotermas (Langmuir e Freundlich) foram ajustadas aos dados experimentais. A significância estatística dos coeficientes de correlação para as isotermas foi o critério pelo qual seus dados foram testados.

\section{RESULTADOS E DISCUSSÃO}

\section{Avaliação do farelo de vôngole como corretivo da acidez do solo}

As curvas de incubação de materiais coletados nos horizontes A e B do LVA com o pó de concha de vôngole, em $\mathrm{pH}$ em água, podem ser visualizadas na Figura 1, e suas respectivas equações, na Tabela 2.

Horizonte A

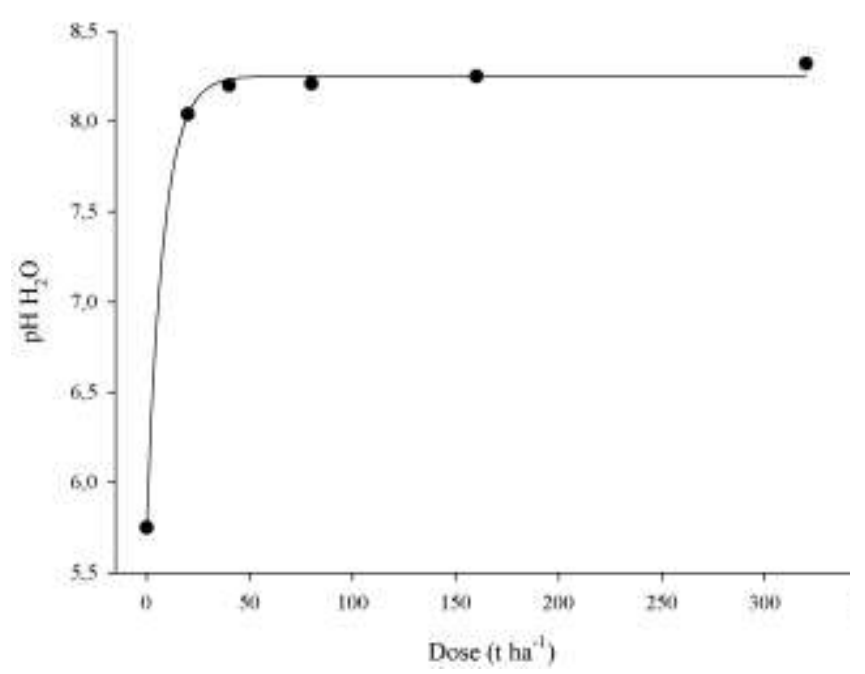

Horizonte B

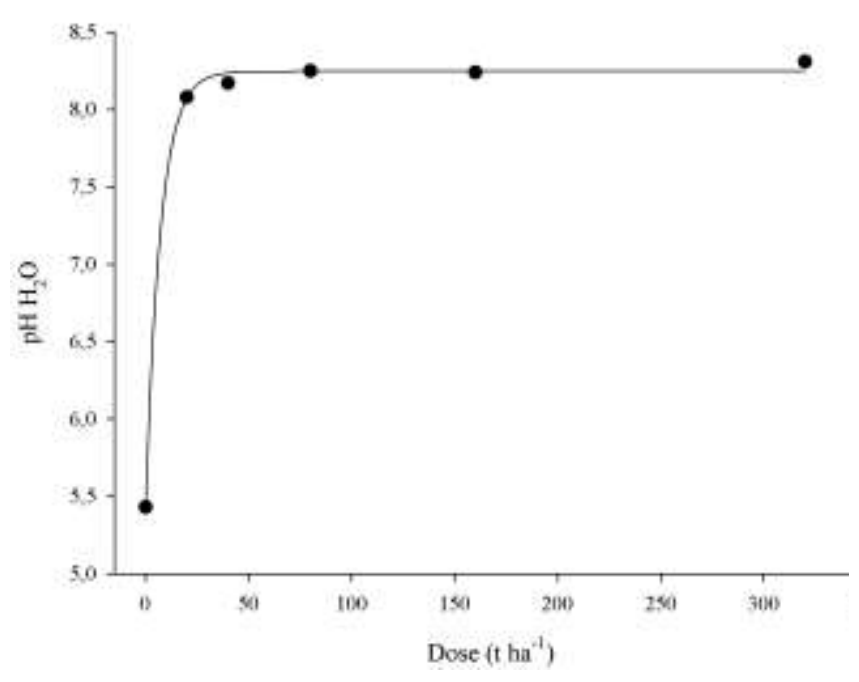

FIGURA 1. Valores de pH em água em função da dose aplicada de pó de concha de vôngole nos horizontes A e B do Latossolo Vermelho-Amarelo distrófico. Values of $\mathbf{p H}$ in water as a function of the applied dose of powdered shell clams in the $A$ and $B$ horizons of the dystrophic Rhodic Haplustox. 
TABELA 2. Equações estimadas do potencial hidrogeniônico $(\mathrm{pH})$ em função da dose (D) para os horizontes A e B e os respectivos coeficientes de determinação. Estimated equations of hydrogenic potential (pH) as a function of dose (D) for $A$ and $B$ horizons and their coefficients of determination.

\begin{tabular}{ccc}
\hline Horizontes & Equação & Coeficiente de determinação \\
\hline $\mathrm{A}$ & $\hat{\mathrm{pH}}=5,750-2,501^{* * *}\left(\mathrm{e}^{-0,122^{* *} \mathrm{D}}-1\right)$ & $\mathrm{R}^{2}=0,99$ \\
$\mathrm{~B}$ & $\hat{\mathrm{pH}}=5,430-2,871^{* *}\left(\mathrm{e}^{-0,13 \text { oै }^{* *}}-1\right)$ & $\mathrm{R}^{2}=0,99$ \\
\hline ** significativo a 1\% de probabilidade. & &
\end{tabular}

Verifica-se, analisando-se a Figura 1, que o farelo de conchas de vôngole proporcionou, mesmo quando adicionado nas menores doses, aumento no $\mathrm{pH}$ do solo, em razão da reação alcalina deste material, o que pode ser explicado pelo relativamente alto PN $(95,40 \%)$.

O aumento no $\mathrm{pH}$ do solo para a faixa 5,5 - 6,5 é desejável, sob ponto de vista agrícola, por proporcionar a disponibilização de muitos macro $(\mathrm{P}, \mathrm{Ca}, \mathrm{S}, \mathrm{N}$ e $\mathrm{K})$ e micronutrientes $(\mathrm{B}$, Mo e outros), além de reduzir a disponibilidade de $\mathrm{Cu}, \mathrm{Fe}, \mathrm{Mn}, \mathrm{Zn}$ e $\mathrm{Al}$, os quais, em excesso, poderiam trazer efeitos tóxicos às plantas. Considerando-se a correção do $\mathrm{pH}$ até 6,5 , a aplicação de uma dose de 2,92 $\mathrm{t} \mathrm{ha}^{-1}$ no horizonte $\mathrm{A}$ já seria suficiente para adequar o solo, no que se refere ao $\mathrm{pH}$, para o cultivo agrícola, quando se tomar, como referência, a curva obtida, medindo-se o pH do solo em água. No caso do horizonte $\mathrm{B}$, a dose necessária é de 3,35 $\mathrm{t} \mathrm{ha}^{-1}$. As doses de farelo de concha de vôngole, obtidas neste trabalho para a correção do $\mathrm{pH}$ do LVA, foram semelhantes às recomendadas por LEE et al. (2008), de 3,4 e 3,8 t ha ${ }^{-1}$, quando utilizaram pó de conchas de ostras para correção do $\mathrm{pH}$ de um solo argiloso e arenoso, respectivamente, e bastante inferiores às encontradas por SILVA et al. (2006), que obtiveram dose de 9,4 $\mathrm{t} \mathrm{ha}^{-1}$, quando aplicaram lodo caleado no mesmo solo utilizado neste experimento. Em ambos os trabalhos, a quantidade do resíduo aplicado foi a suficiente para corrigir o $\mathrm{pH}$ até 6,5, sendo a análise feita em pH em água, tal como neste trabalho.

Os resultados obtidos são indicadores de que o farelo de concha de vôngole é um resíduo relativamente promissor como corretivo da acidez de solos.

\section{Adsorção de fósforo em farelo de vôngole}

As equações das isotermas ajustadas para os modelos de Freundlich e Langmuir e os respectivos coeficientes de determinação estão apresentados na Tabela 3.

TABELA 3. Equações das isotermas ajustadas para os modelos de Freundlich e Langmuir e os respectivos coeficientes de determinação. Isotherm equations adjusted to the Freundlich and Langmuir models and their coefficients of determination.

\begin{tabular}{ccc}
\hline Isotermas & Equação & Coeficiente de determinação \\
\hline Freundlich & $\hat{\mathrm{S}}=0,0252^{++} \times\left(\mathrm{C}_{\mathrm{eq}}\right)^{0,8042^{*}}$ & $\mathrm{R}^{2}=0,976$ \\
Langmuir & $\hat{\mathrm{S}}=\frac{7,056^{++} \times 0,0017^{+} \times \mathrm{C}_{\mathrm{eq}}}{1+\left(0,0017^{+} \times \mathrm{C}_{\mathrm{eq}}\right)}$ & $\mathrm{R}^{2}=0,977$ \\
\hline
\end{tabular}

Em que, ${ }^{*}$ significativo a 5\%; ${ }^{++}$significativo a $10 \%, \mathrm{e}^{+}$significativo a $15 \%$ de probabilidade.

No modelo ajustado de Langmuir, o parâmetro ajustado $0,0017 \mathrm{~L} \mathrm{mg}^{-1}$ é a constante relacionada com a energia de sorção, e $7,056 \mathrm{mg} \mathrm{g}^{-1}$ é a capacidade de sorção do resíduo em relação ao fósforo.

Os ajustes obtidos dos modelos de Freundlich e Langmuir (eqs.(1) e (2)) podem ser considerados razoáveis, como pode ser constatado pelos valores de coeficientes de determinação, e podem ser utilizados para a estimativa das quantidades de $\mathrm{P}$ a serem removidas em função da 
concentração de equilíbrio. No entanto, no caso do fósforo, o modelo de Langmuir tem sido mais utilizado e, por isso, optou-se por discutir o significado dos resultados obtidos para este modelo. Na Figura 2, estão apresentadas as curvas isotermas de adsorção ajustadas para os dois modelos.

O modelo de isoterma de Langmuir baseia-se na hipótese de que a sorção se resume a uma única camada de moléculas da substância sobre a superfície das partículas sólidas, sendo as forças atrativas desenvolvidas entre o sorvente e o sorvido, essencialmente de curta duração (COSTA, 2002). A relação entre a concentração da substância sorvida e a concentração de equilíbrio da mesma na solução é fundamentada no equilíbrio estabelecido entre as velocidades de sorção e de dessorção (FONTES et al., 2000). A análise das formas das curvas de adsorção indica que houve afinidade entre o fósforo e os sítios de adsorção existentes no resíduo. Não deve ser descartado, contudo, que parte dessa remoção de $\mathrm{P}$ da solução possa ser decorrente da formação de fosfato de cálcio e, dessa forma, promovendo remoção do elemento químico por precipitação e não por adsorção ao resíduo.

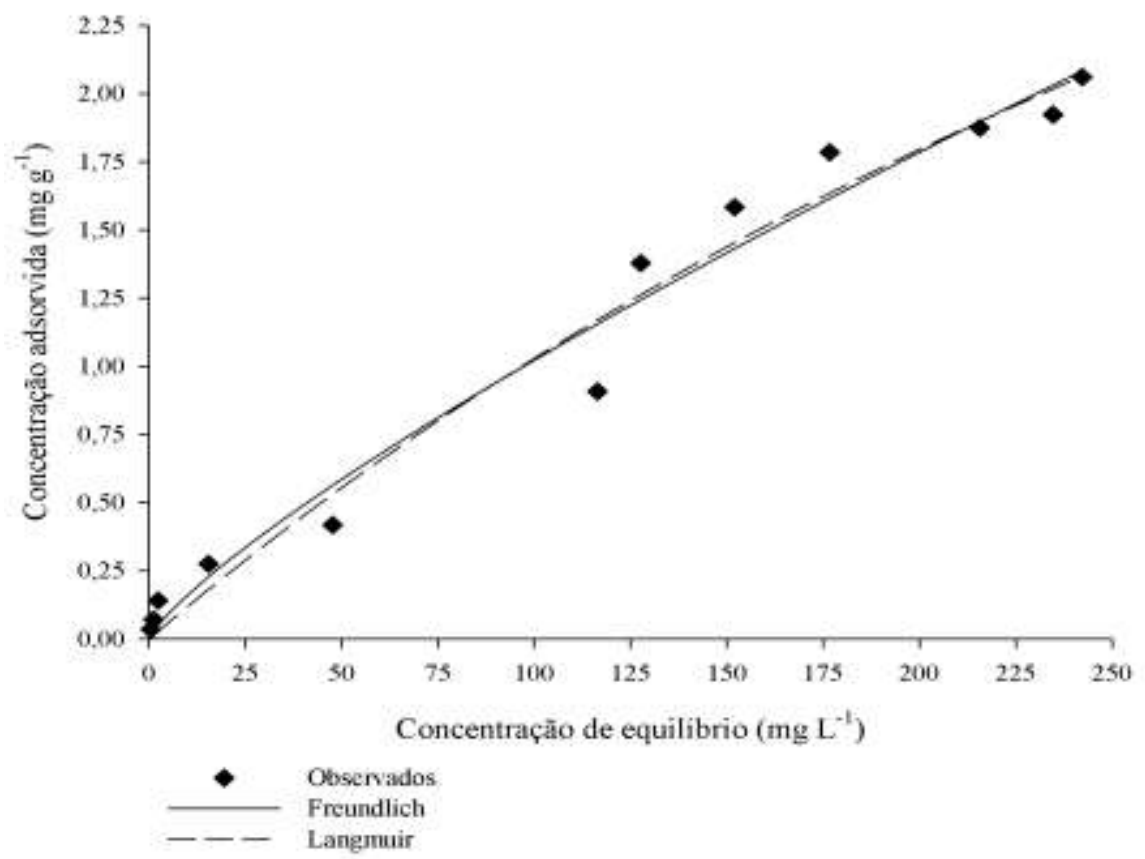

FIGURA 2. Curvas isotermas de adsorção de fósforo ajustadas do modelo de Langmuir e de Freundlich. Adsorption isotherms curves of phosphorus adjusted model of Langmuir and Freundlich.

De acordo com os resultados apresentados na Figura 2, as isotermas de adsorção de P demonstraram que as quantidades desse elemento adsorvidas pelo resíduo aumentaram com a concentração de equilíbrio, corroborando CHAVES et al. (2009b) e FARIAS et al. (2009).

A capacidade máxima de adsorção de $\mathrm{P}$ (aproximadamente $7,056 \mathrm{mg} \mathrm{g}^{-1}$ de resíduo) pelo farelo de vôngole pode ser considerada bastante elevada, quando comparada à adsorção de $\mathrm{P}$ em diversos tipos de solo, tal como citado no trabalho realizado por FARIAS et al. (2009), que encontraram valores de CMAP variando de 0,1448 a $0,3473 \mathrm{mg} \mathrm{g}^{-1}$ em solos mais intemperizados e de 0,0360 a $0,4353 \mathrm{mg} \mathrm{g}^{-1}$ em solos menos intemperizados, de diferentes regiões do Estado da Paraíba, e no de MOREIRA et al. (2006), que obtiveram valores de CMAP variando de 0,1099 a $0,3448 \mathrm{mg} \mathrm{g}^{-1}$ em quatro solos (Cambissolo Háplico, Argissolo Vermelho-Amarelo, Neossolo Regolítico e Latossolo Vermelho-Amarelo) de diferentes regiões do Estado do Ceará. O resultado obtido neste trabalho foi bastante semelhante ao encontrado por MATOS et al. (2010a), que obtiveram CMAP de $7,106 \mathrm{mg} \mathrm{g}^{-1}$ em pó coletado no sistema de tratamento de efluentes atmosféricos gerados em alto-forno siderúrgico, material sabidamente rico em oxi-hidróxidos de Fe. Os autores atribuíram a elevada CMAP à grande interação do $\mathrm{P}$ com os óxidos de Fe e Al. No caso 
deste trabalho, a elevada CMAP obtida pode ser atribuída à grande interação do $\mathrm{P}$ com o Ca existente no farelo de conchas de vôngole.

O fato de apresentar relativamente alta capacidade de sorção é importante indicativo do potencial de utilização do resíduo para remoção de fósforo de, por exemplo, águas residuárias, tornando opção interessante para utilização em sistemas onde se requer remoção desse elemento químico, utilizando-se de técnicas de baixo custo. As conchas podem ser utilizadas, por exemplo, para constituir meio poroso e de suporte em sistemas alagados construídos (FIA et al., 2010a; FIA et al., 2010b; MATOS et al., 2010b) podendo aumentar a eficiência do sistema no que se refere à remoção de $\mathrm{P}$. A necessidade de remoção de $\mathrm{P}$ de águas residuárias decorre do fato de que, se esse elemento químico não for removido eficientemente, poderá proporcionar aumento em suas concentrações em corpos hídricos onde forem lançadas. $\mathrm{O}$ aumento na concentração de $\mathrm{P}$ solúvel nas águas, proporcionando a eutrofização do meio aquático e, como consequência, o desenvolvimento excessivo de algas e macrófitas, o que pode prejudicar os diversos usos benéficos da água, inclusive o potável, além de causar mortandade dos peixes e outros organismos aquáticos.

\section{CONCLUSÕES}

De acordo com os resultados obtidos, pode-se concluir que o farelo de concha de vôngole apresenta relativo potencial de uso como corretivo de acidez do solo, sendo a dose recomendada para correção do pH do horizonte A de um Latossolo Vermelho-Amarelo distrófico de 2,92 $\mathrm{t} \mathrm{ha}^{-1}$, enquanto para correção do horizonte B devem ser usadas $3,35 \mathrm{t} \mathrm{ha}^{-1}$.

Os modelos de Langmuir e Freundlich ajustaram-se bem para representar a isoterma de adsorção de fósforo em farelo de conchas de vôngole. Além disso, este resíduo apresenta boa capacidade de adsorção de fósforo, podendo ter potencial utilização em sistemas de remoção de fósforo de águas residuárias.

\section{REFERÊNCIAS}

BISPO, E.S.; SANTANA, L.R.R.; CARVALHO, R.D.S.; ANDRADE, G.; LEITE, C.C. Aproveitamento industrial de marisco na produção de linguiça. Ciência e Tecnologia de Alimentos, Campinas, v.24, n.4, p.664-668, 2004.

CHAVES, L.H.G.; BRITO, M.E.B.; CARVALHO, A.P.; DANIEL, R.; RIBEIRO, S.; SNATOS, R.T. Adsorção de cobre em amostras de Plintossolo do Estado do Piauí, com diferentes características. Revista Brasileira de Engenharia Agrícola e Ambiental, Campina Grande, v.13, n.3, p.226-232, 2009a.

CHAVES, L.H.G.; CHAVES, I.B.; NASCIMENTO, A.K.S.; SOUSA, A.E.C. Características de adsorção de fósforo em argissolos, plintossolos e cambissolos do Estado da Paraíba. Engenharia Ambiental, Espírito Santo do Pinhal, v.6, n.2, p.130-139, maio/ago. 2009 b.

COSTA, P.O.S. Avaliação em laboratório, do transporte de contaminantes no solo do aterro sanitário de Sauípe-BA. 2002. 171 f. Dissertação (Mestrado) - Pontifícia Universidade Católica, Rio de Janeiro, 2002.

EMBRAPA. EMPRESA BRASILEIRA DE PESQUISA AGROPECUÁRIA. Centro Nacional de Pesquisa de Solos. Manual de métodos de análise de solo. Rio de Janeiro, 1997. 212 p.

FARIAS, D.R.; OLIVEIRA, F.H.T.; SANTOS, D.; ARRUDA, J.A.; HOFFMANN, R.B.; NOVAIS, R.F. Fósforo em solos representativos do Estado da Paraíba. I- isotermas de adsorção e medidas do fator capacidade de fósforo. Revista Brasileira de Ciência do Solo, Viçosa-MG, v.33, p.623-632, 2009.

FIA, R.; MATOS, A.T.; AGUIRRE, C. I. Características químicas de solo adubado com doses crescentes de lodo de esgoto caleado. Engenharia na Agricultura, Viçosa-MG, v.13, n.4, p.287-299, out./dez. 2005. 
FIA, R.; MATOS, A.T.; LAMBERT, T.F.; FIA, F.R.L.; MATOS, M.P. Tratamento das águas do processamento dos frutos do cafeeiro em filtro anaeróbio seguido por sistema alagado construído: II - remoção de nutrientes e compostos fenólicos. Engenharia Agrícola, Jaboticabal, v.30, n.6, p.1.203-1.213, nov./dez. 2010b.

FIA, R.; MATOS, A.T.; MATOS, M.P.; ABREU, E.C.; FIA, F.R.L. Tratamento das águas do processamento dos frutos do cafeeiro em filtro anaeróbio seguido por sistema alagado construído: I - remoção de matéria orgânica. Engenharia Agrícola, Jaboticabal, v.30, n.6, p.1.191-1.202, nov./dez. 2010a.

FONTES, M.P.F.; MATOS, A.T.; COSTA, L.M.; NEVES, J.C.L. Competitive adsorption of zinc, cadmium, copper, and lead in three highly-weathered Brazilian soils. Communications in Soil Science and Plant Analysis, New York, v.31, n.17-18, p.2.939-2.958, 2000.

LEE, C.H.; LEE, D.K.; ALI, M.A.; KIM, P.J. Effects of oyster shell on soil chemical and biological properties and cabbage productivity as a liming materials. Waste Management, Oxford, v.28, n.12, p.2.702-2.708, 2008.

MATOS, A.T. Práticas de tratamento e aproveitamento agrícola de resíduos sólidos. Viçosa-MG: AEAGRI-MG/ DEA/UFV, 2008. 43 p. Série caderno didático, 45.

MATOS, A.T.; COSTA NETO, A.M.; LO MONACO, P.A.V.; EUSTÁQUIO JÚNIOR, V.; MARTINS, M.A. Isoterma de adsorção de fósforo em pó coletado no sistema de tratamento de efluentes atmosféricos gerados na indústria siderúrgica. In: CONGRESSO INTERNACIONAL DE ENGENHARIA SANITÁRIA E AMBIENTAL, 2010. Anais... República Dominicana: ABES, 2010a. 1 CD-ROM.

MATOS, A.T.; FREITAS, W.S.; BRASIL, M.S.; BORGES, A.C. Influência da espécie vegetal cultivada nas condições redox de sistemas alagados construídos. Engenharia Agrícola, Jaboticabal, v.30, n.3, p.518-526, maio/jun. 2010 b.

MOREIRA, D.A.; MARTINEZ, M.A.; SOUZA, J.A.R.; MATOS, A.T.; BATISTA, R.O. Adsorção dos íons $\mathrm{Cu}^{+2}, \mathrm{Cd}^{+2}, \mathrm{~Pb}^{+2}$ e $\mathrm{Zn}^{+2}$ em resíduo sólido urbano. Engenharia na Agricultura, Viçosa-MG, v.17, n.5, p.346-352, set./out.2009.

MOREIRA, D.A.; MARTINEZ, M.A.; SOUZA, J.A.R.; REIS, C.; REIS, E.L.; BARROS, F.M. Capacidade máxima de adsorção de $\mathrm{Cd}, \mathrm{Cu}, \mathrm{Pb}$ e $\mathrm{Zn}$ em resíduos da construção civil. Ambi-água, Taubaté, v.5, n.2, p.112-118, 2010.

MOREIRA, F.L.M.; MOTA, F.O.B.; CLEMENTE, C.A.; AZEVEDO, B.M.; BOMFIM, G.V. Adsorção de fósforo em solos do Estado do Ceará. Revista Ciência Agronômica, Fortaleza, v.37, n.1, p.7-12, 2006.

NOVAIS, R.F.; SMITH, T.J. Fósforo em solo e planta em condições tropicais. Viçosa: UFV, DPS, 1999. $399 \mathrm{p}$.

OLIVEIRA, L.F.C.; LEMKE-DE-CASTRO, M.L.; RODRIGUES, C.; BORGES, J.D. Isotermas de sorção de metais pesados em solos do cerrado de Goiás. Revista Brasileira de Engenharia Agrícola e Ambiental, Campina Grande, v.14, n.7, p.776-782, 2010.

PARK, W.H.; POLPRASERT, C. Roles of oyster shells in an integrated constructed wetland system designed for P removal. Ecological Engineering, Oxford, v.3, n.4, p.50-56, 2008.

PRADO, R.M.; FERNANDES, F.M.; NATALE, W. Efeito residual da escória de siderurgia como corretivo de acidez do solo na soqueira de cana-de-açúcar. Revista Brasileira de Ciência do Solo, Viçosa-MG, v.27, n.2, p.287-296, 2003.

SILVA, N.C.L.; LUIZ, F.A.R.; MONTEBELLER, C.A.; MACHADO, N.S.; MATOS, A.T. Utilização de lodo de esgoto doméstico caleado como corretivo de solo. In: II SIMPÓSIO MINEIRO DE ENGENHARIA AMBIENTAL, 2006. Anais... Viçosa: UFV, 2006. 1 CD-ROM. 
SOUZA, R.S.; CHAVES, L.H.G.; FERNANDES, J.D. Isotermas de Langmuir e de Freundlich na descrição da adsorção de zinco em solos do Estado da Paraíba. Revista Brasileira de Ciências Agrárias, Recife, v.2, n.2, p.123-127, abr./jun. 2007.

TITO, G.A.; CHAVES, L.H.G.; RIBEIRO, S.; SOUZA, R. S. Isotermas de adsorção de cobre por bentonita. Caatinga, Mossoró, v.21, n.3, p.16-21, jul./set. 2008. 